http:/ / dx.doi.org/10.5007/1982-5153.2016v9n1p293

\title{
Avaliação de Uso de AVA no Ensino de Física
}

(Evaluation of Use a VLE in the Physics Teaching)

\section{ANDRESON LOPES DE LACERDA e TATIANA DA SILVA}

\author{
Universidade Federal de Santa Catarina (andrelopescg@gmail.com, tatiana.silva@ufsc.br)
}

Resumo. Os ambientes virtuais de aprendizagem (AVA) ampliam as possibilidades e iniciativas de produção de cursos, disciplinas e atividades baseadas no contexto online. Neste contexto, investigamos as percepções de alunos e de professores em ambiente real de aprendizagem desenhado para apoio a uma disciplina de Física presencial em nível universitário. Ele foi elaborado para ampliar a sala de aula presencial com base nos elementos do design instrucional (DI), adequação aos conteúdos e à diversidade de sujeitos presentes neste espaço. A análise é feita utilizando-se estatística descritiva simples e análise de conteúdo das respostas dadas a um questionário e a entrevistas aplicados pelos pesquisadores aos participantes da proposta. A avaliação demonstra que o DI cumpriu com seus objetivos. Os alunos e professores entendem a importância da utilização de diversos meios e recursos para apoiar o aprendizado, a flexibilização da sala de aula e a colaboração entre pares. Os resultados obtidos fornecem subsídios para o levantamento de questões acerca da utilização de AVA como apoio ao ensino presencial, particularmente para o ensino de Física.

Abstract. Virtual learning environments (VLE) expand the possibilities and initiatives of courses production, disciplines and activities based on online context. In this context, we investigated the perceptions of students and teachers in virtual learning environment designed to support a discipline of physics classroom at the university level. It is designed to enlarge the face-to-face classroom taking into account the elements of instructional design (ID) for their suitability to the content and the diversity of subjects present in this space. The analysis is done using simple descriptive statistics and content analysis of the answers given in a questionnaire administered by researchers and interviews with participants engaged in the research. The evaluation shows that the DI has met its objectives. Students and teachers understand the importance of using various means and resources to support learning, the flexibility of the face-to-face classroom and the collaboration among peers. The results show an understanding of what was carried out and brings benefits to survey questions about the use of AVA to support teaching, particularly for physics teaching.

Palavras-chave: ambientes virtuais de aprendizagem, design instrucional, ensino superior de física Keyword: virtual learning environments, instructional design, physics higher education

\section{Introdução}

Vivemos uma revolução tecnológica e não podemos fugir da construção de práticas educacionais que atendam a essa demanda. A disseminação e a popularização de computadores e a rápida expansão da Internet, smartphones, tablets, redes sem fio e móveis e a proliferação das redes sociais exercem uma pressão com relação ao uso da informática também na educação. A emergência por mudança em decorrência dos avanços alcançados pela ciência da computação se soma às constatações de necessidade de mudanças na educação tradicional. Conforme apontado por Moran et al. (2000), muitas das formas de ensinar hoje já não se justificam mais, pois perdemos muito tempo, aprendemos pouco e, por conseguinte, nos desmotivamos.

Nós, professores e pesquisadores, sabemos que um uso puramente instrumental da tecnologia, claramente alijado daquelas características que vêm em seu bojo: comunicação, compartilhamento e co/autoria não nos permite alcançar os objetivos de 
aprendizagem. Tornam-se imperativos a construção de práticas, de metodologias de ensino e de aprendizagem e de elaboração e uso de materiais didáticos a partir de reflexões e investigações que nos permitam entender e explicitar sob que condições as tecnologias podem atuar como instrumentos para a criação de espaços que viabilizem uma educação baseada não mais na exclusiva apresentação de conteúdos, mas com a intenção de propiciar o desenvolvimento de habilidades e competências cognitivas que de fato sirvam a processos de aprendizagem dinâmicos.

Os Ambientes Virtuais de Aprendizagem (AVA) aparecem, nesse cenário, como espaços possíveis para a integração de conteúdos e de atividades de aprendizagem que promovam a colaboração entre os participantes. É possível estabelecer uma sinergia entre aulas presenciais e atividades virtuais, flexibilizando e ampliando os tempos e espaços de ensino-aprendizagem até agora praticamente restritos à sala de aula. Compactuamos com Martín-Barbero (2014) que a aprendizagem escapa hoje das demarcações de idade e das limitações temporais que facilitam sua inscrição em um só tipo de lugar, visto que os saberes que se ensinam na escola encontram-se hoje atravessados por saberes do ambiente tecnocomunicativo, regido por outras modalidades e ritmos de aprendizagem que os distanciam do modelo de comunicação tradicional acadêmico.

No caso da Física, em particular, a diversificação de recursos didáticos e sua integração com atividades colaborativas podem auxiliar no processo de ensino e de aprendizagem. Ela é normalmente vista como uma disciplina de difícil compreensão nos vários níveis de ensino. Para exercitar um pensar mais científico, o ensino de física mediado por tecnologias digitais educacionais deve promover a interação com os conteúdos (links no texto, com o uso de simulações, jogos, vídeos, a inclusão de perguntas a serem respondidas no próprio ambiente tecnológico), a percepção visual de variações temporais de grandezas físicas (abstratas ou não), a utilização de animações e simulações que permitem uma representação visual dos fenômenos estudados, facilitando a compreensão de modelos matemáticos, tornando-os mais significativos e próximos da realidade dos alunos, a busca por informações adicionais sobre o conteúdo em outras fontes. Tudo isso faz com que os alunos assumam uma participação ativa no seu processo de aprendizagem e faz com que estejam no centro desse processo.

A natureza adaptativa do computador oferece vantagens para ampliar as metodologias de ensino. Os alunos podem pesquisar ideias e conceitos, realizar 
experimentações, explorações e modelagens por vezes inacessíveis pelas estratégias tradicionais de ensino (DE HAAN, 2005). Quando usada corretamente, a tecnologia não só permite apresentar o material didático de diversas maneiras, mas também oferece fácil acesso à riqueza de recursos disponíveis na Internet, o que por sua vez pode ser útil para o desenvolvimento de estratégias e atividades centradas no aluno (CHANG et al., 2006).

Nesse contexto, o papel dos professores se redimensiona e passam a precisar produzir e/ou selecionar materiais disponíveis que se adéquam ao perfil de seus alunos e ao nível de ensino em questão. Em nossa opinião, mais do que participar desses deslocamentos provocados pelas tecnologias, o docente precisa reconhecer o potencial educacional imbricado a esse contexto, para assim fomentar práticas pedagógicas orientadas, flexíveis e condizentes com esse espaço-tempo em que se vive. Assim, há profundas mudanças nas dinâmicas educacionais, não só na redefinição do papel desempenhado pelo professor, mas também do papel desempenhado pelo aluno e do papel desempenhado pela avaliação. A integração de recursos computacionais pode viabilizar também um trabalho mais colaborativo entre professores na organização de espaços virtuais, desenvolvimento de ambientes de aprendizagem e trocas de experiências na perspectiva de construção de conhecimento.

Objetiva-se aqui apresentar, a partir de um recorte da dissertação de mestrado de Lacerda (2013), as percepções de alunos e de professores a respeito do uso de um material didático digital desenhado em um ambiente virtual de aprendizagem para apoio a uma disciplina de Física presencial em nível universitário. O AVA foi estruturado para se tornar um espaço possível com vistas a ampliar a sala de aula presencial. Para tal, o material didático precisou ser planejado e adequado aos conteúdos e à diversidade de sujeitos presentes naquele espaço.

\section{O cenário}

A emergência dos AVA ampliou as possibilidades e iniciativas de produção de cursos, disciplinas e atividades baseadas no contexto online. Não obstante, tais iniciativas têm exigido das instituições de ensino superior, em particular, a adoção de iniciativas que tendem a ultrapassar os vieses tradicionais ou convencionais das questões relacionadas ao ensino e à aprendizagem. A Universidade Federal de Santa Catarina (UFSC) adota a plataforma Moodle para utilização nos cursos ofertados na modalidade a distância e também como apoio aos cursos presenciais. No entanto, o 
simples fato de oferecer acesso a uma interface dessa natureza não garante que a sua utilização seja realizada de modo a aproveitar todo seu potencial. Em muitos casos, esses espaços têm sido utilizados como repositório de textos, listas de exercícios e outros materiais digitalizados (SILVA et al., 2010).

A proposta de pesquisa foi a de investigar as possibilidades e potencialidades de um AVA, desenhado e implementado para apoiar uma disciplina de Física presencial e que explorasse de maneira adequada os recursos que ele oferece. Buscaram-se no design instrucional (DI) os caminhos mais pertinentes para a estruturação e a apresentação dos conteúdos de modo a integrá-los de maneira interativa com estratégias de aprendizagem propostas através de adoção de uma linguagem diversificada. A ação intencional e sistemática de ensino, envolvendo o planejamento, o desenvolvimento e a utilização de métodos, técnicas, atividades, materiais, eventos e produtos educacionais em situações didáticas específicas, apontada por Filatro (2007) como sendo uma definição pertinente para o design instrucional, surge como propósito de facilitar a aprendizagem humana a partir dos princípios de aprendizagem e instrução conhecidos e fundamentados em teorias cognitivas de aprendizagem.

A partir da percepção dos alunos e de professores pretende-se respaldar metodologias diferenciadas para auxiliar o ensino e a aprendizagem na modalidade de ensino presencial mediados por AVA, particularmente no ensino de Física, visto que ainda são escassas as pesquisas e discussões sobre o papel do design instrucional em Educação em Ciências (BRICK et al., 2011).

Escolheu-se uma disciplina de Física ofertada para um curso de engenharia da UFSC ministrada no período que compreendeu a pesquisa. É uma disciplina teórica do quadro de disciplinas ofertadas pelo Departamento de Física para esse curso e é realizada em 72 horas-aula mais 36 horas complementares. As aulas foram conduzidas de forma expositiva, utilizando o quadro de giz, com resolução de exercícios. Ela teve como objetivo conduzir o aluno a adquirir uma visão conceitual sobre ondas, ótica, eletrodinâmica, relatividade e mecânica quântica. Ao final da disciplina o aluno deve ser capaz de fazer cálculos simples utilizando ferramentas da teoria ondulatória, da termodinâmica básica, da relatividade e da física quântica. Os conteúdos abordados e elencados na ementa da disciplina são: ondas em meios elásticos, temperatura, calor e a primeira lei da termodinâmica, oscilações eletromagnéticas, ondas eletromagnéticas, 
natureza e propagação da luz, reflexão e refração, interferência, difração, redes de difração e espectros, polarização, luz e física quântica, ondas e partículas.

A proposta de desenvolver um material didático digital para evidenciar a interatividade entre professor-aluno-conteúdo se aliou ao desafio de incluir esses elementos ao extenso conteúdo da disciplina. Ao mesmo tempo buscava-se contribuir para o entendimento das questões relacionadas ao uso de AVA no ensino presencial. Encontrou-se, portanto, no design instrucional (DI) elementos que colaboram para evidenciar suas potencialidades pedagógicas.

No DI em questão utilizou-se o modelo proposto por Ally (2004) baseado na convergência de pressupostos teóricos do ensino e da aprendizagem e que visa atender às diferenças e aos ritmos dos alunos. No modelo as estratégias de aprendizagem são definidas em quatro eventos distintos, o primeiro denominado de "Preparação", onde são elaboradas atividades para preparar o aluno para o conteúdo. O segundo e o terceiro eventos, chamados de "Atividades de aprendizagem e Interação", nos quais as atividades devem ser propostas de modo a propiciar interação entre alunos e professores, alunos e conteúdos, alunos e interface e entre alunos e alunos. O quarto evento denominado de "Transferência" é onde são propostas as atividades nas quais os alunos possam demonstrar o que o conteúdo proporcionou de significado pessoal e para a aplicação em outros contextos (LACERDA, 2013).

Nesse sentido, o material elaborado propõe diferentes estratégias e usa diferentes linguagens. Foi elaborado com características de hipermídia, propondo-se acesso não linear aos conteúdos através de organizadores gráficos desenvolvidos pelo designer instrucional e também através da ampla exploração de ferramentas e de recursos do Moodle para oferecer uma gama de atividades e de estratégias didáticas. Para exemplificar, lançou-se mão do Book e da Lição, Glossário, Fórum, Laboratório de Avaliação, Enquete e da Wiki. Buscou-se encontrar uma adequação destes recursos ao evento do modelo em questão e aos objetivos de aprendizagem.

Optamos por primeiro desenvolver um estudo-piloto selecionando-se um dos conteúdos, o de Relatividade Restrita. Essa escolha justifica-se pelo fato de se tratar de um tema de difícil assimilação e compreensão por parte dos alunos (ANGOTTI et al., 1976; FELIPE et al., 2005) e por possuir bibliografia e pesquisa em ensino de Física escassa em nível de graduação. A dificuldade normalmente encontrada no ensino dessa teoria é o nível de abstração exigido pelos conceitos, que são difíceis e, geralmente, transcendem a experiência do estudante. Após o seu desenvolvimento, aplicação e 
avaliação no semestre de 2011.2, ampliamos em 2012.1 para todos os conteúdos abordados. Além disso, na perspectiva de colaboração entre professores, o material do estudo-piloto foi utilizado em duas outras disciplinas de Física. Assim, apresentamos a análise feita a partir da percepção dos participantes estudantes e professores universitários envolvidos como sujeitos da pesquisa.

No estudo que aqui se apresenta o designer instrucional foi responsável pela avaliação inicial dos conteúdos do programa da disciplina e posterior organização e estruturação no AVA, pela proposição das estratégias de aprendizagem, pela criação do discurso visual, pela indicação e implementação de ferramentas e pelo fornecimento de suporte técnico durante a realização da disciplina. O professor foi responsável pela criação dos roteiros dos conteúdos e das atividades, pela indicação da bibliografia, elaboração das estratégias dentro das propostas apresentadas pelo designer instrucional, aplicação das atividades e avaliação dos alunos. Os encontros entre a equipe ocorriam com uma frequência de três vezes por semana ou mais, de acordo com as necessidades.

O material completo está disponível para acesso no Moodle, através do link (https://moodle.ufsc.br/course/view.php?id=30608) ${ }^{1}$. O conteúdo do estudo-piloto se encontra publicado em Lacerda e Silva (2015a; 2015b) e Lacerda (2013).

\section{Coleta e análise de dados}

Os dados foram coletados e organizados no próprio AVA (Moodle) e os instrumentos utilizados para a avaliação segundo a percepção de alunos e professores foram dois questionários e entrevistas.

Utilizamos um questionário exploratório aplicado no estudo-piloto (semestre 2011.2) disponibilizado no AVA com a finalidade de obter elementos para uma avaliação mais consistente, de modo a orientar a condução da proposta e sua consequente ampliação. E, o outro questionário desenvolvido por Hsu et al. (2009) aplicado na ampliação da proposta (semestre 2012.1) validado estatisticamente e que foi construído com o objetivo de estabelecer critérios padrão de avaliação de plataformas web viabilizando-se a comparação entre diferentes plataformas. Em ambos os

\footnotetext{
${ }^{1}$ Para acessar o Moodle UFSC - Apoio aos Cursos Presenciais é necessário nome de usuário e senha, porém em casos excepcionais a Superintendência de Governança Eletrônica e Tecnologia da Informação e Comunicação (SeTIC), responsável pelo gerenciamento do Moodle na instituição, permite, mediante solicitação a criação de espaços nos quais é possível o acesso de visitantes. $\mathrm{O}$ material em questão foi disponibilizado obedecendo a essa especificidade. Desse modo, através do link supracitado qualquer usuário pode acessá-lo, não sendo possível apenas a participação nas atividades propostas.
} 
questionários buscaram-se coletar informações sobre os seguintes indicadores: apresentação dos conteúdos e propostas das atividades como melhoria para a aprendizagem, adequação estética do conteúdo apresentado, as ferramentas utilizadas para leitura e para realização das atividades e ofereceu-se um espaço para sugestões e críticas por parte dos alunos.

As entrevistas foram feitas para ampliar ainda mais as questões em debate, bem como aprofundar a análise dos resultados respaldada nas opiniões dos participantes. Elas ocorreram sempre no período de finalização do conteúdo programático da disciplina, para que os alunos pudessem primeiro participar das atividades propostas. $\mathrm{O}$ convite para a participação nas entrevistas deu-se livremente para todos os envolvidos. Nesses termos optou-se por não eleger uma amostra específica dentro do universo de participantes, possibilitando que sem critérios, estes pudessem dialogar sobre a experiência que acabavam de vivenciar.

As questões utilizadas na entrevista tiveram como base as dimensões extraídas dos questionários, ou seja, os entrevistados foram questionados seguindo os mesmos aspectos tratados no questionário disponível para análise da sua percepção. No entanto, sob a perspectiva de diálogo e sob a ótica de questões semiestruturadas. Sendo assim, questionou-se sobre qual a percepção que eles tiveram sobre as estratégias de aprendizagem utilizadas nas atividades elaboradas e de que maneira o professor as conduzia. Em relação ao material didático questionou-se sobre a percepção obtida nesse aspecto. Quanto às ferramentas de aprendizagem, questionou-se sobre a facilidade/dificuldade para a realização das atividades. No que tange a interface de aprendizagem, os entrevistados foram questionados sobre a diversificação da linguagem, sobre os aspectos gráficos utilizados na proposta. E, por fim, solicitava-se que acrescentassem mais explanações sobre como perceberam a proposta.

Também foram entrevistados os professores que lançaram mão do material didático desenvolvido para o ambiente virtual de aprendizagem. Desse modo participaram das entrevistas dois professores e mais o professor responsável pela disciplina escolhida para ancorar a pesquisa.

As questões elaboradas para a entrevista com os professores versavam sobre: a) AVA no ensino presencial, nesse aspecto buscava-se identificar apontamentos que evidenciasse a utilização do Moodle como apoio ao ensino presencial, quais as dificuldades ou problemas de ensino/aprendizagem que levou o professor entrevistado a recorrer a tal proposta; b) a utilização de AVA desenhado para o ensino de Física, como 
forma de entender quais aspectos convergem para sua importância no ensino e aprendizagem dessa área de conhecimento; c) a integração durante o processo de equipes multidisciplinares ou do designer instrucional, de modo que fossem identificadas questões para evidenciar recuos ou avanços na introdução desses elementos no ensino presencial; d) a possibilidade de compartilhar com outros professores propostas baseadas em Tecnologias Digitais de Informação e Comunicação (TDIC) desenvolvidas para a sala de aula presencial e, e) solicitava que os professores entrevistados assinalassem pontos de destaque, positivos ou negativos na proposta utilizada por eles em sala de aula e desenvolvida por terceiros.

\section{Resultados}

Apresentam-se os resultados obtidos a partir da análise dos dados dos questionários e das entrevistas para as duas etapas de implementação da proposta didática, ou seja, estudo-piloto e material completo em AVA. A análise é feita tanto quantitativamente utilizando-se de estatística descritiva simples e análise de conteúdo. A estatística descritiva (BABBIE, 2003) constitui-se num método de se apresentar descrições quantitativas de forma manejável e uma delas é utilizando-se a redução dos dados (categorização) e uso de frequências, por isso, "simples". A análise do conteúdo (BARDIN, 1977) é um procedimento amplo e extremamente diversificado cujo espectro vai da objetividade à subjetividade. Neste trabalho envolveu pré-análise dos dados, inferência e interpretação (recorte, enumeração e classificação) (GIL, 2008, p. 152). Dessa forma, as perguntas discursivas dos questionários e das entrevistas passaram por uma redução, ou seja, identificaram-se semelhanças nas respostas que foram agrupadas em categorias que surgiram do discurso verbal e foram concernentes aos elementos constitutivos do DI. A disciplina escolhida para a investigação e que foi envolvida nas duas etapas é nomeada Disciplina $\mathrm{A}$, as duas disciplinas que utilizaram o material de Relatividade Restrita (RR) de forma complementar são nomeadas Disciplina B e Disciplina C. Na "B" o conteúdo de RR fazia parte do final do programa da disciplina e na "C" era considerado como pré-requisito para um dos conteúdos abordados. A tabela 1 apresenta o número de respondentes e de entrevistados por disciplina. 
Tabela 1 - Número de alunos matriculados e respondentes por disciplina

\begin{tabular}{|c|c|c|c|c|c|}
\hline Semestre & Disciplina & $\begin{array}{c}\text { Alunos } \\
\text { matriculados }\end{array}$ & $\begin{array}{l}\text { Respondentes do } \\
\text { questionário }\end{array}$ & $\begin{array}{l}\text { Percentual de } \\
\text { respondentes }\end{array}$ & $\begin{array}{c}\text { Número de } \\
\text { entrevistados }\end{array}$ \\
\hline 2011.2 & $\begin{array}{l}\text { Disciplina } \\
\text { A: Estudo } \\
\text { Piloto }\end{array}$ & 30 & 15 & $50 \%$ & 3 \\
\hline \multirow{3}{*}{2012.1} & $\begin{array}{l}\text { Disciplina } \\
\text { A: Design } \\
\text { completo }\end{array}$ & 34 & 7 & $21 \%$ & 2 \\
\hline & $\begin{array}{l}\text { Disciplina } \\
\text { B: } \\
\text { Relatividade } \\
\text { Restrita }\end{array}$ & 14 & 3 & $21 \%$ & 1 \\
\hline & $\begin{array}{c}\text { Disciplina } \\
\text { C: } \\
\text { Relatividade } \\
\text { Restrita }\end{array}$ & 35 & 3 & $8 \%$ & 1 \\
\hline
\end{tabular}

Fonte: Os autores

A partir da análise dos comentários e das respostas aos questionários na fase do Estudo Piloto foi possível identificar na percepção dos respondentes que as atividades propostas e o DI desenvolvido foram bem recebidos por eles. Além disso, fez reconhecer aspectos preponderantes no planejamento, implementação e aplicação de atividades desses espaços. A orientação dentro de cada tópico se mostrou comprometida nesse estudo porque se ressentiu de um feedback do próprio sistema que auxiliasse o aluno a se localizar dentro do próprio ambiente, ou seja, relatórios de atividades informando-o sobre o que foi realizado e o que não foi, a exemplo do que aparece para o professor. No semestre 2012.1 a versão do Moodle foi atualizada para a versão 2.0. Tal versão possui características que convergem com a filosofia da Web 2.0, dentre elas, a integração com repositórios online, a exemplo do canal de vídeos YouTube. Essa nova versão trouxe também a possibilidade de configurar o curso de modo que um relatório de atividades fosse exibido para o participante. Ele mostra ao aluno a sua atividade no curso, assim como listagens das suas contribuições, tais como mensagens do fórum ou submissões de tarefas. No caso particular dessa disciplina, embora essa configuração estivesse habilitada, optou-se por uma redundância mantendo-se também um "bloco de notas" com as atividades as quais os alunos deveriam realizar.

Para o conteúdo de Relatividade Restrita utilizou-se o conjunto de eventos instrucionais propostos no modelo de Ally (2004). Contudo, na ampliação do DI para os demais conteúdos, optou-se por adotar em alguns conteúdos uma ou algumas das 
estratégias e em outros conteúdos a adoção completa do modelo. Além disso, os diferentes assuntos envolvidos na disciplina acomodam os eventos instrucionais em maior ou menor grau e pode-se adotar a estratégia de primeiro fazer com que os estudantes se familiarizem com uma proposta de trabalho que não se ancora apenas no tempo de sala de aula e às diferentes ferramentas do AVA para depois utilizá-la em sua plenitude.

$\mathrm{Na}$ avaliação do ambiente completo utilizou-se um $\mathrm{O}$ questionário validado utilizado foi desenvolvido por Hsu et al. (2009) que contempla os elementos constitutivos do design instrucional e os divide em quatro dimensões que são: Estratégia de Aprendizagem (EA), Material Didático (MD), Ferramentas de Aprendizagem (FA) e Interface de Aprendizagem (IA). Cada dimensão é composta por um conjunto de categorias que somadas chegam ao total de 22. Cada categoria é composta por seus respectivos indicadores, que por sua vez são os itens de questões os quais os respondentes foram convidados a se posicionarem. No total é composto por 39 itens (questões) e faz uso da escala Likert com cinco níveis de satisfação: 1 = discordo totalmente; 2 = discordo; 3 = indiferente; 4 = concordo; 5 = concordo totalmente. Para sistematização e análise dos dados, utilizou-se estatística descritiva simples e o Ranking Médio (RM) (OLIVEIRA, 2005) para obter o grau de concordância em cada uma das quatro dimensões contempladas no questionário e para obter o grau de concordância geral. Ele é definido como uma média ponderada:

$$
R M=\frac{\sum_{i=1}^{5} i \times N R}{\sum_{i=1}^{5} N R}
$$

Onde $\mathrm{NR}_{\mathrm{i}}$ é o número de respondentes que atribui o grau de concordância $\mathrm{i}$ da escala Likert. Numa escala Likert com cinco níveis de satisfação, os valores menores do que três são considerados como discordantes, os maiores do que três como concordantes e iguais a três como indiferentes. Na Tabela 2, apresenta-se o RM obtido por dimensão (RMD) e por categorias (RMC) com seus respectivos indicadores. 
Tabela 2 - Ranking Médio por categorias e por dimensão

\begin{tabular}{lcc}
\hline Dimensões e categorias & RMC & RMD \\
\hline Estratégia de aprendizagem & 3,9 & \\
\hline Objetivo Instrucional & 3,8 & \\
Avaliação & 3,5 & \\
Suporte & 3,8 & \\
Outras estratégias & 3,8 & 3,7 \\
Ensino & 3,8 & \\
Comunicação & & \\
\hline Material didático & 3,6 & \\
\hline Precisão & 3,8 & 3,8 \\
Divisão dos parágrafos & 3,8 & \\
Variedade & 3,6 & \\
Adequação & 3,8 & \\
Sistematização & 3,6 & \\
Clareza nos tópicos & & \\
\hline Ferramentas de aprendizagem & 3,2 & \\
\hline Ferramentas do sistema & 3,7 & \\
Facilitação do ensino & 3,5 & \\
Função de ligação & 3,0 & \\
Usabilidade & 3,5 & \\
Design de navegação & 3,8 & \\
\hline Interface de aprendizagem & 3,0 & \\
\hline Texto & 3,6 & \\
Imagem & & \\
Animação & & \\
Vídeo & & \\
Design de interface geral & & \\
\hline Fonte: Os a, & \\
\hline
\end{tabular}

Fonte: Os autores

Apesar de poucos respondentes por turma, os estudantes que responderam ao questionário o fizeram de forma consistente e pontuaram os elementos constitutivos da avaliação de um DI e da qualidade de um material instrucional. Tem-se que o RM das Estratégias de Aprendizagem e da Interface de Aprendizagem foi igual a 3,8; o Material Didático teve um RM resultante de 3,7 e as Ferramentas de Aprendizagem um RM de 3,5. Portanto, na escala de concordância aqui utilizada os valores maiores do que 3 do cálculo do RM são considerados concordantes, a proposta de DI apresentada alcançou resultados satisfatórios. É possível também obter o RM geral do design instrucional 
desenvolvido para a disciplina. Na Tabela 3 é possível identificar que um percentual de $65 \%$ do índice de concordância, concorda ou concorda totalmente com a proposta.

Tabela 3 - Frequências e escala de concordância geral do DI da disciplina

\begin{tabular}{ccccccc}
\hline $\begin{array}{c}\text { Concordo } \\
\text { totalmente }\end{array}$ & Concordo & Indiferente & Discordo & $\begin{array}{c}\text { Discordo } \\
\text { Totalmente }\end{array}$ & Não se Aplica & $\begin{array}{c}\text { Total } \\
\text { RM }\end{array}$ \\
132 & 197 & 75 & 60 & 23 & 20 & 507 \\
$26 \%$ & $38,9 \%$ & $14,8 \%$ & $11,9 \%$ & $4,5 \%$ & $3,9 \%$ & 3,7 \\
\hline
\end{tabular}

Fonte: Os autores

Quanto às entrevistas, nessa segunda etapa, foram entrevistados ao todo 4 alunos (A1, A2, A3 e A4) e 3 professores, o professor da Disciplina A (P1), o professor da Disciplina B (P2) e o professor da Disciplina C (P3). O procedimento foi semelhante ao adotado no estudo-piloto, elas foram realizadas em local escolhido pelos entrevistados e estes assinaram um termo de consentimento o qual permitia aos pesquisadores utilizar suas falas e comentários de forma anônima.

As questões da entrevista semiestruturada versam sobre as dimensões levantadas anteriormente, estas aqui entendidas como elementos constitutivos de um design instrucional para AVA. Nesses termos, tem-se como categorias de análise para a percepção dos alunos: estratégias de aprendizagem, material didático, ferramentas de aprendizagem e interface de aprendizagem. A seguir, primeiro apresenta-se a percepção dos alunos e, em seguida, a percepção dos professores.

\section{Percepção dos alunos}

a) Quanto às estratégias de aprendizagem: os entrevistados destacaram a maneira como o professor da sua disciplina conduziu as aulas tendo o Moodle como apoio; a diversificação da linguagem, a variação também dos formatos das atividades; a importância na interação entre alunos; processos de reflexão em diferentes níveis de complexidade criados ou estimulados pelas questões propostas nas atividades. As falas a seguir exemplificam essas inferências:

A1: Teve atividade assim: a professora levantou debates em grupo. Ela fez um debate, uma discussão. O que a professora proporcionou no Moodle ela trouxe pra aula. Ela tentou não ser monótona, porque às vezes os professores do departamento são muito monótonos e a professora sempre trazia objetos [experimentos], tinha o Moodle, os vídeos que ela trazia. Então eu vi que ela queria diversificar [...] mas achei muito útil à combinação das aulas com o ambiente foi bastante proveitoso. 
A3: Como eu não conhecia muita coisa dos conteúdos, pra mim qualquer pergunta que fosse ali eu tinha que refletir. Eu refleti bastante! "O que é que é isso? O que é que é aquilo? será que eu sei?" Aí tentava responder. Tanto que depois o professor em sala de aula pegou algumas questões e fez perguntas com o que nós tínhamos respondido no Moodle, mas sem dizer quem tinha respondido, aí eu pensava: "Será foi eu que respondi essa ou não?" Daí ele explicava. E aí foi bom porque tu já tinha refletido antes.

b) Quanto ao material didático: nessa dimensão os entrevistados apontaram aspectos importantes a serem discutidos, como, por exemplo, a utilização do material didático disponível no AVA como um guia, desconsiderando-se o livro didático. Talvez por uma questão de tempo disponível para o estudo, sintam-se compelidos a decidir sobre qual material é mais útil. Entretanto, é importante salientar que em nenhum momento foi solicitado para se optar por esse ou por aquele material e que alguns alunos percebem a necessidade de um maior aprofundamento, de que é preciso pesquisar para poder responder às questões propostas no AVA. Outras menções em relação ao material didático referem-se à sua estruturação e à clareza dos objetivos pretendidos. Também foram citados os materiais de apoio disponibilizados nos tópicos dos conteúdos, os quais, de acordo com os entrevistados, contribuíram com os estudos, particularmente, nos períodos próximos das provas. A fala a seguir demonstra esses aspectos:

\begin{abstract}
A4: Eu acho que lá no AVA tem mais possibilidades, porque tinha bastantes links, tinha bastante "saiba mais" que nos levava a mais textos e como tu tá no virtual a gente tem mais possibilidade de buscar um pouco mais se tu tá com dúvida em uma palavra é só usar o Google e pesquisar ali. Agora se você tem só o livro didático, sem ter um computador por perto fica mais difícil. Como era final de semestre eu fiz mais o que o professor sugeriu, mas os textos, mesmo os que não eram obrigatórios eu li tudo e gostei de ter o material lá. Achei um material interessante.
\end{abstract}

c) Quanto às ferramentas de aprendizagem: os entrevistados expuseram suas opiniões quanto às facilidades e dificuldades encontradas para a realização das atividades. Reconhecem as deficiências e as potencialidades das ferramentas. As observações dos entrevistados servem também para a reflexão da equipe multidisciplinar, fornecendo elementos para uma autoavaliação:

A1: O Moodle não é perfeito, mas mais do que o Moodle ser perfeito e não ser perfeito, depende muito de quem organiza, depende muito da organização de quem organiza. Outras coisa é a respeito do gabarito [feedback], às vezes a ferramenta aceita duas respostas, mas foram erros aceitáveis. Mas eu considero que foram problemas superficiais, mas a contribuição foi bem maior.

A3: As ferramentas eu achei fáceis, mas mesmo no final eu ficava com dúvida: 'será que a resposta foi?' Daí depois eu clicava e via que foi! Às 
vezes a gente tem medo de responder e depois não enviar, sem saber se a reposta foi enviada.

Embora se tenha buscado ao máximo evitar problemas de ordem técnica fica evidente que em grande parte os problemas fogem do controle da equipe multidisciplinar, alcançando instâncias de ordem administrativas do Moodle, sendo necessário recorrer, no caso da UFSC, ao setor responsável pelo gerenciamento geral e infraestrutura administrativa do Moodle customizado para a instituição.

d) Quanto à interface de aprendizagem: nessa dimensão, os entrevistados expuseram suas opiniões sobre os aspectos concernentes ao discurso visual utilizado no design instrucional da disciplina e diversificação dos meios utilizados no material didático disponibilizado. Nas falas a seguir é possível identificar que os alunos reconhecem a importância da organização visual do ambiente virtual de aprendizagem:

A1: Houve muitos aspectos bons. A questão da organização, sinceramente assim eu nunca vi o Moodle tão organizado, tão assim caprichado, tanto do aspecto de conteúdo, quando do aspecto visual, foi bem rico a contribuição. Total! Pra mim fez bastante diferença. Eu vi que houve um esforço bastante grande nessa parte. Geralmente quando eu uso o Moodle em outras disciplinas tem um 'topicozinho' (sic) lá. Nessa disciplina foi bem diferente houve desenhos, animações, houve simulações bem características, houve vídeos, atividades... muito bom... A interface e o conteúdo foram os dois que chamaram mais atenção.

As falas dos entrevistados reforçam e evidenciam a importância da diversificação da linguagem nos materiais existentes no AVA. Embora ainda se perceba um "quê motivacional", por exemplo, na fala do Aluno3 entende-se que as imagens, os vídeos, cores e movimentos das animações podem promover muito mais do que motivação.

A3: Te confesso que aquelas figurinhas, aquelas coisas chamam a atenção do aluno. Então aquilo ali chamava bastante atenção. Os vídeos 'né'? Sei lá é diferente! As figuras chamam a atenção, tu olha aquelas figuras, tu clica nos quadradinhos [referindo-se ao organizador gráfico] daí já surge aquele texto, tu já lê aquilo ali. Tudo bem interessante.

Na fala do Aluno2, a seguir, é possível perceber que este reforça que o apoio dos vídeos e das demais mídias ali existentes, se afasta dos aspectos motivacionais e se aproxima das possibilidades de aprendizagem. No caso específico de um fenômeno da Física, os vídeos com a representação de tal fenômeno, aliadas às exposições do professor em sala de aula presencial auxiliaram o aluno passou a entender melhor o conteúdo. 


\begin{abstract}
A2: Tudo era bem claro, logo que terminava um conteúdo já havia os novos tópicos, tinha um 'topicozinho' com as atividades para realizar. Uma parte que me chamava atenção foi o apoio audiovisual, ou seja, vídeos de experimentos. É a coisa mais interessante pra você entender um experimento científico. É você vê-lo sendo executado e com os recursos da Internet principalmente o YouTube você acha praticamente tudo, todos os tipos de experimentos. Eu me baseei em videoaulas onde era feito toda a demonstração dos cálculos e eu comparava com os da professora e formulava os meus, usando os vídeos. Às vezes na aula tinha demonstração de vídeos, mas não dá tempo de fazer isso em todos os experimentos, e colocando lá no Moodle era só clicar que já tinha o link, às vezes só o fato de dizer procure o vídeo no YouTube o cara não tem vontade de ir procurar, mas já estando ali é sempre mais fácil.
\end{abstract}

Outro aspecto presente no comentário do Aluno2 é a interconexão existente dos materiais existentes no Moodle com o universo virtual, com as ferramentas da Internet, tais como os canais de vídeos, reforçando a proposição do DI e do AVA propostos na perspectiva da educação online. Não obstante, percebe-se a importância da integração de metodologias, quadro, vídeos, atividades no Moodle e laboratórios didáticos. Cada um tem seu papel e sua união pode trazer benefícios ao aprendizado.

A seguir serão apresentados os resultados obtidos nas entrevistas realizadas com os professores das disciplinas que fizeram uso do material desenvolvido.

\title{
Percepção dos professores
}

As questões da entrevista realizada com os três professores (P1, P2 e P3) versavam sobre possibilidades, na perspectiva docente, propiciadas pela utilização do ambiente virtual de aprendizagem como: apoio ao ensino presencial, AVA como possibilidade de ampliação da prática docente, AVA como possibilidades para o ensino de Física, integração de outros profissionais compondo equipes multidisciplinares e as possibilidades de compartilhar o material com outros professores.

a) AVA como apoio ao ensino presencial: nessa categoria os professores entrevistados apontam que o AVA possibilita um espaço a mais para a ampliação das discussões. É possível perceber também que dentre os aspectos mencionados por eles estão o aumento do interesse dos alunos e também a dificuldade de tempo para conduzir as discussões no ambiente virtual de aprendizagem.

P2: Como apoio, eu acho extremamente favorável. Os alunos mostram bastante interesse por tudo que é virtual, tudo que tem na Internet, parece que tem um atrativo pros alunos, então eu percebi que os alunos nos deram um retorno muito bom. Foi muito positivo, a gente caiu naquela questão: na falta de tempo, da minha inexperiência em trabalhar com conteúdos online, porque eu estava colocado aquilo de forma passiva, o conteúdo lá. Essa coisa mais ativa de você colocar o conteúdo lá e o aluno tem que acessar, tem que 
interagir com você, tem que responder aos questionários, é uma coisa mais ativa foi uma coisa nova pra mim, eu percebo que eles gostam disso, eles mostram interesse nesse tipo de atividade, então se eles mostram interesse nada mais natural do que você usar pra tentar realmente passar o conteúdo e é aquela questão de experiência que com o passar do tempo você aprende a administrar isso e saber usar o conteúdo.

b) AVA como possibilidade de ampliação da prática docente: nessa categoria os entrevistados destacaram como pontos positivos a possibilidade de o AVA tornar possível a elaboração de metodologias inovadoras e possibilitar a reutilização o material, adequando-o de acordo com o público. Como ponto negativo aponta-se que essas possibilidades oneram o trabalho do professor. Nas falas dos entrevistados é possível também observar menções sobre as dificuldades dos alunos se expressarem nos espaços virtuais de interação. O entrevistado a seguir evidencia em seus comentários a potencialidade do AVA no que concerne a interação entre o professor, o aluno e os conteúdos. No entanto, aponta resistências por parte dos alunos em se expressarem formalmente nas questões propostas, nos fóruns de discussão.

P3: Eu vejo como uma possibilidade a mais e não fica restrito ao espaço da sala de aula, você pode disponibilizar os materiais das aulas tudo isso fica disponível pro aluno acessar, no momento em que ele achar interessante. Vejo como uma possibilidade a mais de interação entre professor-aluno, pra interação entre o aluno e o conteúdo, pra interação entre os próprios alunos. Muitas vezes você pensar nessas ferramentas como fóruns, chats então é uma possibilidade a mais. Agora os alunos eles resistem um pouco. Do ponto de vista dos alunos, é difícil esse feedback, e quando você pede um discussão mais aprofundada eles ficam fechados mesmo. Pelas poucas experiências que eu já tive com o Moodle, eu percebo uma resistência grande por parte dos alunos. Muitas vezes eles até olham o material, mas quando você coloca questões sobre o material, pede informações sobre o material, você demora a ter uma resposta, não significa dizer que eles não olham, eles olham, mas quando você pede pra escrever alguma coisa...quando você chega na aula eles até falam alguma coisa, mas quando precisam escrever ou participar eles têm bastante resistência.

c) AVA como possibilidades para o ensino de Física: no que concerne a utilização dos recursos e ferramentas do AVA para o ensino de Física, os professores destacaram a diversificação da linguagem, a facilidade para a visualização de fenômenos físicos, a proposição de diferentes estratégias, como pontos positivos, no entanto, acrescenta-se como ponto negativo a dificuldade da escrita matemática nas ferramentas disponíveis.

P2: A facilidade que você encontra em colocar simulações e vídeos com demonstrações [...]. A própria facilidade que a gente encontra hoje de ter videoaulas, mesmo. Você poder usar o Moodle como um link para videoaulas, seminários que estão online. A facilidade de você ter acesso a experimentos, applets que você possa visualizar o fenômeno ocorrendo. 
Acho que o que assusta muito nos conteúdos da Física é a questão conceitual, é sempre a questão conceitual que assusta todo mundo [...] é uma questão que os alunos têm muita dificuldade de entender. Então o Moodle com essa facilidade gráfica de você mostrar as coisas visualmente ajuda a trabalhar os conceitos [...]. Então essas questões gráficas aqui ajudam na compreensão e isso faz falta. Embora os livros-textos tenham esses conteúdos, mas é impressionante como eles gostam de ver isso na Internet, eles se identificam mais com o conteúdo que está na rede. Eu percebi isso. Foi uma experiência nova, mas deu pra perceber isso claramente.

P3: Quanto ao Moodle eu só acho limitado em alguns pontos como, por exemplo: quando o aluno vai precisar escrever uma equação, por exemplo,quando ele precisa inserir um gráfico ainda é difícil pro aluno fazer isso no Moodle, tirando isso eu acho uma coisa completamente útil pra educação.

\section{d) Integração de outros profissionais compondo equipes multidisciplinares: a} inserção dessa questão nas entrevistas com os professores se justifica pelo fato de que na presente pesquisa, propõe-se a integração de profissionais de diferentes áreas do conhecimento no desenvolvimento de design instrucional para AVA também no ensino presencial. Nas falas a seguir é possível observar que os professores veem de maneira positiva essa integração. Percebem essa integração como uma parceria válida, a qual promove olhares diferentes para a mesma situação. É evidente também nos comentários dos entrevistados a importância do professor na condução dos trabalhos. Na fala de P2 destaca-se ainda a atuação do professor ao longo de todo o processo de planejamento. $\mathrm{O}$ professor participa com as questões formais sobre o conteúdo e os demais profissionais o adéquam à proposta que está sendo desenhada. No entanto, é importante frisar que o que se está propondo, nesse trabalho, é que os profissionais que participam da equipe multidisciplinar não são apenas executores de ações técnicas, mas também participam do pensar pedagógico. Propõe-se que estes enxerguem nas ferramentas, nos recursos possibilidades e potencialidades capazes de ultrapassar a lógica tecnicista.

P2: Acho que a contribuição de profissionais de outras áreas ela é vital. Porque, por exemplo, você precisa de alguém que conheça de programação e conheça as linguagens dos recursos mais atuais. [...] Então se você quer fazer uma demonstração de um fenômeno físico, você tem uma ideia, você sabe a Física, sabe as equações, mas alguém tem que colocar aquilo de uma forma competente, a pessoa precisa ter conhecimento. É claro que tem que ter a interface com profissionais de várias áreas, [...]. O físico dá a contribuição formal, coloca o que ele quer passar, e evidente: a gente tem uma noção de como estruturar isso de uma forma acessível, mas os outros profissionais precisam entrar, com a diagramação, com a programação, com a facilidade de acesso das informações e aí vai se construindo o ambiente de maneira que seja realmente útil, porque não adianta você ter tudo lá, num ambiente e vai ficar perdido lá. 
e) Possibilidade de compartilhar o material com outros professores: essa questão surge quando os professores das disciplinas B e C concordaram em adotar o material para ser utilizado em suas disciplinas. Parte-se do pressuposto que um material didático desenhado para um AVA, particularmente quando obedece aos princípios da linguagem hipermidiatizada e assume um caráter de objeto digital de aprendizagem (WILEY, 2000), torna-o possível ser reutilizado em outros contextos, guardando as devidas especificidades e características do contexto onde será utilizado. Por se tratar de uma mesma plataforma (o Moodle UFSC) torna-se ainda mais evidente a possibilidade de importação do material. Outra característica a ser colocada, é a de que as ferramentas utilizadas para a apresentação dos conteúdos e para a realização das atividades estão abertas a adaptações e são reeditáveis. Tal característica possibilita ao professor adaptar o material aos seus objetivos e ao público da sua disciplina. Na fala a seguir essas evidências tornaram-se mais claras.

P3: A comunidade científica compartilha informação, querendo ou não muitos trabalhos são feitos baseados em outros trabalhos já existentes, muitas atividades de pesquisa já usam dados de outros pesquisadores então eu acho completamente válido e abre um canal a mais de comunicação até entre professores de diferentes disciplinas eu de certa maneira sou um entusiasta do uso das novas tecnologias, mesmo se você for olhar dentro da comunidade você tem certas resistências mesmo por arte dos professores quanto por parte dos alunos.

O comentário de P3 faz uma analogia entre a troca possível de material didático entre os professores com o compartilhamento de informações da própria comunidade científica. Considera também uma abertura a mais para a comunicação entre os docentes.

Os resultados obtidos através das entrevistas evidenciam a compreensão do que foi realizado e traz subsídios para o levantamento de questões acerca da utilização de ambientes virtuais de aprendizagem como apoio ao ensino presencial, particularmente, para o ensino de Física.

\section{Considerações finais}

Assumimos como objetivo desenvolver um material didático digital para ambiente virtual de aprendizagem que evidenciasse a interatividade entre professoraluno-conteúdo, de modo a contribuir para o entendimento das questões relacionadas ao uso desses espaços no ensino presencial, buscando no design instrucional elementos que 
colaborassem para evidenciar suas potencialidades pedagógicas, tendo como cenário o ensino de Física.

Os alunos avaliaram o DI da disciplina e essa avaliação demonstra que o design instrucional cumpriu com seus objetivos porque eles entendem que é importante a utilização de diversos meios e recursos para apoiar o aprendizado.

Foi possível compartilhar o DI da disciplina com outros professores para evidenciar a possibilidade de utilização de um projeto dessa natureza em diferentes contextos e situações. Estes professores também avaliaram a proposta e as suas falas trazem à tona questões relacionadas à comunicação entre os docentes, à troca de experiências entre estes e a importância de outros profissionais compondo equipes para o desenvolvimento de materiais didáticos para ambientes virtuais. Na entrevista, trouxeram questões como o tempo de dedicação ao planejamento de projetos dessa natureza que pode ocasionar um aumento da carga de trabalho, não apenas no planejamento, mas principalmente na avaliação dos alunos nesses espaços.

Ressaltamos que uma iniciativa como esta visa constituir-se em alternativa para a elaboração de novos saberes e estratégias metodológicas de ensino na busca por ampliar fronteiras no campo de pesquisa em ensino de ciências, particularmente em ensino de Física. Esperamos que esta pesquisa possa contribuir com mais reflexões, bem como apontar novos caminhos e possibilidades para futuros estudos que busquem relacionar design instrucional, ambiente virtual de aprendizagem e ensino de Física e aprofundamentos nas questões referentes às demandas entre a inserção das tecnologias digitais na educação em qualquer que seja sua modalidade, em qualquer que seja o seu nível.

\section{Agradecimentos}

A produção desse material teve financiamento do MEC/CAPES no âmbito do edital "O Uso da Tecnologia da Informação e Comunicação na Formação dos Alunos do Curso de Física Presencial" (Edital No 15 de 23 de março de 2010). Aos alunos e professores participantes da avaliação da proposta didática.

\section{Referências}

ALLY, M. Foundations of educational theory for online learning. In: ANDERSON, T.; ELlOUMI, F. (Org.). Theory and Practice of Online Learning. Canadá: Printed at Athabasca University, 2004. p. 3-31. Disponível em: 
<http://cde.athabascau.ca/online_book/pdf/TPOL_book.pdf > . Último acesso em: 06 out. 2011.

ANGOTTI, J. A. P.; DELIZOICOV, D.; PERNAMBUCO, M. M. C. A.; RUDINGER, E. Um módulo de relatividade: ciclo básico. In: SIMPÓSIO NACIONAL DE ENSINO DE FÍSICA, 3. v. Especial, n. 3, 1976, São Paulo. Anais... São Paulo, 1976. Disponível em: <http://www.sbfisica.org.br/v1/arquivos_diversos/SNEF/III/III-SNEF-InformativoVol-3.pdf $>$. Último acesso em: 13 jul. 2012.

BABBIE, E. Métodos de Pesquisa de Survey. Belo Horizonte: Ed. UFMG, 2003.

BARDIN, L. Análise de Conteúdo. Lisboa: Edições 70, 1977.

BRICK, E. M.; SOARES NETO, F. F.; HOFFMAN, M. B. Os papeis do designer instrucional nos cursos de licenciatura em física e matemática da UFSC na modalidade a distância. In: ENCONTRO NACIONAL DE PESQUISADORES EM EDUCAÇÃO EM CIÊNCIAS, 8, Campinas, 2011. Anais... Campinas, 2011. Disponível em: $<$ http://www.adaltech.com.br/testes/abrapec/resumos/R0071-1.pdf $>$. Último acesso em: 12 jan. 2013.

CHANG, K. E.; SUNG, Y. T.; HOU, H. T. Web-based tools for designing and developing teaching materials for integration of information technology into instruction. Educational Technology \& Society, v.9, n.4, p. 139-149, 2006.

DE HAAN, R. L. The impending revolution in undergraduate science education. Journal of Science Education and Technology, v. 14, n. 2, p. 253-269, jun. 2005. Disponível em: <http://wikifuse.pbworks.com/f/DeHaan+2005.pdf>. Último acesso em: 15 fev. 2013.

FILATRO, A. Design instrucional contextualizado: educação e tecnologia. São Paulo: Pearson, 2007.

FELIPE, G.; BARROSO, M. F.; PORTO, C. M. Simulações computacionais no ensino de relatividade restrita. In: SIMPÓSIO NACIONAL DE ENSINO DE FÍSICA, 16, Rio de Janeiro, 2005. Anais... Rio de Janeiro, 2005. Disponível em: $<$ http://www.if.ufrj.br/ marta/aplicativos/2005-snef16-aplicat-relat.pdf >. Último acesso em: 08 ago. 2011.

GIL, A. C. Métodos e técnicas de pesquisa social. 6. ed. São Paulo: Atlas, 2008.

HSU, C.; YEH, Y.; YEN, J. Development of design criteria and evaluation scale for web-based learning platforms. International Journal of Industrial Ergonomics, v. 1, n. 39, p. 90-95, jan. 2009.

LACERDA, A. L. Contribuições do design instrucional ao ensino presencial de Física apoiado por Ambiente Virtual de Aprendizagem. Dissertação de mestrado em Educação Científica e Tecnológica - Universidade Federal de Santa Catarina, Florianópolis, 2013.

LACERDA, A. L.; SILVA, T. Possibilidades pedagógicas na perspectiva de uma educação online. Caderno Brasileiro de Ensino de Física, v.32, n.1, p. 157-179, 2015a. 
Disponível em:< $\quad$ https://periodicos.ufsc.br/index.php/fisica/article/view/21757941.2015v32n1p157>. Último acesso em: 26 mai. 2015.

LACERDA, A. L.; SILVA, T. Materiais e estratégias didáticas em ambiente virtual de Aprendizagem. Revista Brasileira de Estudos Pedagógicos, v.96, p. 321-342, 2015b. Disponível em: <http://rbep.inep.gov.br/index.php/RBEP/article/viewFile/3378/2210>. Último acesso em: 03 set. 2015.

MARTÍN-BARBERO, J. A comunicação na educação. São Paulo: Contexto, 2014.

MORAN, J. M.; MASSETO, M. T.; BEHERENS, M. A. Novas tecnologias e mediação pedagógica. 16. ed. Campinas: Papirus, 2000.

OLIVEIRA, L. H. Exemplo de cálculo de ranking médio para Likert. Notas de Aula: Metodologia Científica e Técnicas de Pesquisa em Administração. Varginha: PPGA CNE/FACECA, 2005. Disponível em: $<$ http://mail.administradores.com.br/producaoacademica/ranking-medio-para-escala-de-likert/28/download/ > Último acesso em: 01 dez. 2012.

SILVA, T.; FLORES, C. R.; ERN, E.; TANEJA, I. J. Expansão do Ensino Superior: panorama, análises e diagnósticos do curso de licenciatura em Física a distância da Universidade Federal de Santa Catarina. Caderno Brasileiro de Ensino de Física, v.27, n.3, p. 528-548, $2010 . \quad$ Disponível em: <http://www.periodicos.ufsc.br/index.php/fisica/article/view/21757941.2010v27n3p528/17172>. Último acesso em: 01 jul. 2011.

WILEY, D. A. Connecting learning objects to instructional design theory: a definition, a metaphor, and a taxonomy. In: WILEY, D. A. (Ed.). The instructional use of learning objects: online version. Utah: Utah State University, 2000. p. 1-35. Disponível em: <http://reusability.org/read/chapters/wiley.doc>. Último acesso em: 28 dez. 2011.

ANDRESON LOPES DE LACERDA. Graduado em Comunicação Social (UEPB), Mestre em Educação Científica e Tecnológica (UFSC) e Doutorando em Educação (UFSC). Supervisor Educacional (FAPEU) atendendo aos cursos de Física e de Matemática na modalidade de educação a distância (UAB/UFSC) como coordenador de AVA, oferecendo suporte e formação aos professores e tutores para uso de ambientes virtuais de aprendizagem. Atua também como consultor em tecnologias e mídias na educação (presencial e a distância). Ministra minicursos e oficinas (teóricos e práticos) para professores e profissionais da educação em diversos níveis, sobre temas relacionados às tecnologias digitais de informação e comunicação, sobre mídias na educação. Participa do grupo de Pesquisa Comunic (UFSC) no qual participa de projetos sobre formação crítica do sujeito em espaços sociais virtuais e educação.

TATIANA DA SILVA. Doutora em Física (IF/UFRJ), Professora Associada I do Departamento de Física (UFSC). Experiência em desenvolvimento de materiais didáticos hipermídia para educação na modalidade a distância tendo coordenado a equipe de Webfísica dos cursos de licenciatura do Consórcio CEDERJ, com experiência em formação continuada de professores e elaboração de materiais didáticos digitais. Participou dos projetos "Avaliações Educacionais e o Ensino de Matemática e 
Ciências", apresentado pela Universidade Federal do Rio de Janeiro em resposta ao Edital No 038/2010/CAPES/INEP, dentro do Programa Observatório da Educação; CARONTE (Conteúdos de Astronomia para o ensino apoiado em Tecnologias) submetido ao Edital MCT/CNPq/SECIS no 63/2008 - Popularização da Astronomia e do projeto de pesquisa "TIC/Física" de fomento ao uso das Tecnologias de Comunicação e Informação nos cursos de Graduação e de favorecimento da institucionalização de métodos e práticas de ensino-aprendizagem para a convergência entre as modalidades de educação presencial e a distância (CFM/UFSC) Edital n ${ }^{\circ} 15$ de 23 de março de 2010. Atuou como coordenadora de área física do Programa Institucional de Bolsas de Iniciação à Docência (PIBID/UFSC) de março de 2009 a dezembro de 2013. É orientadora de mestrado e doutorado do PPGECT/UFSC e integrante do Grupo de Pesquisa em Ensino de Física (FSC/CFM/UFSC).

Recebido: 25 de agosto de 2015

Revisado: 14 de dezembro de 2015

Aceito: 21 de janeiro de 2016 